\title{
Modelo multidimensional para o controle da dengue: uma proposta com base na reprodução social e situações de riscos*
}

\section{| ' Solange Laurentino dos Santos, ${ }^{2}$ Lia Giraldo da Silva Augusto |}

Resumo: O objetivo do artigo consiste em apresentar e discutir um modelo compreensivo/explicativo, de caráter ecossistêmico, sobre o processo de transmissão da dengue nos níveis de micro e macrocontexto, a partir da identificação das situações de riscos envolvidas. Considerou-se a dengue como doença infecciosa viral de transmissão vetorial que traz, na sua dinâmica de transmissão, elementos das dimensões biológicas, de conduta, ecológicas, políticas e econômicas, o que a caracteriza como um problema complexo e exige um enfoque sistêmico para seu controle. Assim, para a construção da modelagem, utilizaram-se o enfoque teórico da reprodução social de Juan Samaja e seus condicionantes de macro e microcontexto, e o enfoque operativo ecossistêmico, que buscou responder à pergunta condutora desta construção: quais são as situaçôes de risco para transmissão da dengue, considerando as diversas dimensões da "reprodução social da saúde" no nivel local? A visão ampliada das inter-relações entre as diversas situações de risco envolvidas na determinação multidimensional da dengue poderá servir como eixo direcionador para uma gestão integrada das ações do programa de controle da doença, articuladas entre os diversos setores envolvidos.

\author{
1 Professora adjunta do \\ Departamento de Medicina \\ Social da Universidade Federal \\ de Pernambuco; Doutorado em \\ Saúde Pública pelo Centro de \\ Pesquisas Aggeu Magalhães / \\ Fiocruz em Recife. Endereço \\ eletrônico: solange.Isantos@ \\ ufpe.br \\ ${ }^{2}$ Médica; docente pesquisadora \\ titular do Centro de Pesquisas \\ Aggeu Magalhães; professora \\ adjunta da Universidade \\ de Pernambuco. Endereço \\ eletrônico: giraldo@cpqam. \\ fiocruz.br
}


A dengue, doença infecciosa viral de evolução geralmente benigna, de transmissão vetorial pelo mosquito Aedes aegypti Linaeus, 1762, que traz, na sua dinâmica de transmissão, elementos dos condicionantes biológicos, comportamentais, ecológicos, políticos e econômicos, caracteriza-se como um problema complexo e exige um enfoque sistêmico para o seu controle.

Nas últimas décadas, tem sido reconhecida, mundialmente, como uma das doenças de maior impacto na saúde pública. Ressurge como uma potencial pandemia global, posto que no mundo estima-se que mais de dois bilhôes e meio de pessoas, que vivem em áreas com a presença do vetor, apresentam-se em condições favoráveis à transmissão do vírus. Mais de 100 países têm informado a presença da doença em suas populações (na África, nas Américas, no leste Mediterrâneo, Sudeste da Ásia e Pacífico Ocidental); neles, estima-se que ocorram 50 milhōes de novos casos a cada ano. Em relação aos casos graves, com manifestação hemorrágica (denominada de Febre Hemorrágica da Dengue - FHD), mais de 500.000 casos anuais requerem hospitalização. No entanto, a letalidade desses casos é baixa, desde que recebam adequada assistência médica (OMS, 2002; 2006; OPAS, 2003).

Apesar dos esforços despendidos na elaboração de estratégias para o enfrentamento do problema, Santos (2003) apresentou alguns contrapontos dos principais elementos responsáveis pela baixa efetividade dos programas e dentre esses a questão do uso de produtos químicos para o controle vetorial é uma ação que vem recebendo críticas de autores como Augusto et al. (2000) e Novaes et al. (2006), quanto à eficácia desses produtos e aos efeitos deletérios à saúde e ao meio ambiente.

Esses questionamentos têm levantado perguntas diante das situações de incertezas em relação à saúde das populações submetidas aos modelos adotados, além das altas somas de recursos gastos. No ano de 2002, por exemplo, foi gasto mais de um bilhão para o controle da Dengue no Brasil, sendo 85\% desse valor destinados à vigilância e controle vetorial (BRAGA; VALLE, 2007). Essas situações de incertezas são a ocorrência de novas epidemias, a endemização; a circulação de novos sorotipos; o aumento da incidência do agravamento das intercorrências clínicas; o acometimento, cada vez mais, de pessoas nas faixas etárias mais jovens e a manutenção dos altos índices de infestação vetorial, na maioria dos municípios, além da resistência vetorial aos inseticidas empregados 
pelo PNCD (BRASIL, 2008; LIMA, 1999; SANTOS, 2003).

Diante disso, impõe-se a necessidade de se pensarem modelos que integrem os diversos condicionantes que compõem a complexa causalidade da doença, valorizando os aspectos socioambientais do processo saúde-doença; a interdisciplinaridade na produção do conhecimento; a intersetorialidade e participação social no planejamento e nas ações, sendo uma necessidade reconhecida hoje por diversos centros de pesquisa e de organizaçôes internacionais que atuam no campo da saúde e do desenvolvimento técnico-científico.

Neste artigo defende-se um modelo compreensivo/explicativo de caráter ecossistêmico, a partir da identificação das situações de risco envolvidas com a transmissão da Dengue nos níveis de micro e macrocontexto. Para isso, considerase necessário resgatar alguns autores que fazem uma análise multidimensional da compreensão do processo saúde-doença, da reprodução social e situação de saúde e da determinação socioambiental da Dengue.

\section{A reprodução social como perspectiva para uma análise multidimensional da compreensão do processo saúde- doença}

Dentre os modelos existentes sobre a explicação do caráter multidimensional no processo saúde-doença, este artigo será conduzido a partir da compreensão da situação de saúde vista na perspectiva da teoria dos Sistemas Complexos Adaptativos, cujos autores de referência foram Rolando Garcia, Pedro Luis Castellanos e Juan Samaja e que servem de fundamentos teóricos para a discussão desse problema. Por esse motivo, considera-se importante iniciar pelo entendimento dos conceitos de "complexidade/complexo" e de "reprodução social", que são fundantes para a compreensão desse modelo interpretativo.

Segundo Garcia (2002, p. 55), não há definição para o substantivo "complexidade". O que se define é o adjetivo "complexo" e que será usado no entendimento da expressão "sistemas complexos", que deve ser entendida como "sistemas não-decomponiveis ou semidecomponiveis", como cita:

São sistemas constituídos de processos determinados pela confluência de múltiplos fatores que interagem de tal maneira que não se pode separá-los. Em consequência, o sistema não pode ser descrito adequadamente, nem seu funcionamento explicado, pela mera adição de enfoques parciais provenientes de estudos independentes de cada um dos seus componentes. Num sistema não decomponível, os diferentes componentes somente po- 
Ainda segundo esse autor, a pesquisa de um sistema definido como complexo apresenta sérias dificuldades. Pode seu estudo ser feito de maneira rigorosa se o pesquisador se atém a alguns princípios gerais que ordenem a análise, de forma a não cair na generalização estéril de que, num sistema complexo, "tudo interage com tudo", distinguindo os princípios da organização e o da evolução para a análise da questão complexa:

Quando estudamos um complexo empírico determinado, não podemos analisar "todos" os seus elementos, não apenas devido a uma impossibilidade material, mas também por razōes práticas. [...] É inevitável, portanto, que cada estudo estabeleça relaçôes entre um número limitado de elementos abstraidos do complexo. Mas toda abstração significa considerar alguns aspectos do complexo e não outros. Obviamente, quando um elemento é "abstraído", e outros deixados de lado, é porque já fizemos uma interpretação desse elemento (GARCIA, 2002, p. 56, grifo do autor).

As considerações de Pedro Luis Castellanos (1997) sobre as relações existentes entre a situação de saúde e as condiçôes de vida, na definição do processo de produção e reprodução social, buscaram compreender a realidade natural e social em que se vive e com a qual se trabalha. $\mathrm{Na}$ sua visão, essa realidade é complexa e composta de inúmeros objetos, seres e processos. Essa complexidade não é anárquica e possui uma organização, uma arquitetura, que mantém relação com os processos que deram origem a esses objetos e seres e que explicam as qualidades e os comportamentos de cada um deles. Herber Simon (1981 apud CASTELLANOS, 1997) e outros autores descrevem a arquitetura do mundo em natural e artificial - entendendo como artificial tudo que é produzido pelo ser humano - como sistemas complexos e hierárquicos e quase passíveis de serem decompostos e, nos quais, cada objeto de estudo que se aborda como totalidade é, na realidade, um subsistema de outros sistemas maiores, no seio dos quais interage com outros subsistemas de seu mesmo nível. Ainda segundo esse autor, o objeto de estudo está estruturado internamente por subsistemas de nível inferior de complexidade, que interagem entre si, em que a realidade é revelada como sistema complexo e aberto, com um número praticamente infinito de níveis organizacionais acima e abaixo do nível no qual se situa o estudo ou intervenção.

Qualquer que seja o nível de abordagem, esse fará parte de um sistema maior e estará integrado por sistemas menores, cada um dos quais correspondendo a uma totalidade 
em um nível de organização inferior da realidade. [...] parecidos com as famosas

caixas chinesas e as bonecas russas, em que, a cada vez que abrimos uma caixa ou boneca, aparece outra menor a qual, em si mesma, é também o mesmo objeto ainda que de menor tamanho e complexidade (CASTELLANOS, 1997, p. 41).

A cada nível de organização, se verificam qualidades emergentes que não se observam nos níveis inferiores, mas como potencialidades próprias desse nível. Saber qual das totalidades é a correta constitui algo que depende do problema sob estudo. Por isso, a delimitação do problema de investigação tem de incluir, necessariamente, uma delimitação do nível de abordagem, podendo ser o micro e/ou o macrocontexto.

Esse autor convida a compreender a saúde como resultante de conteúdos que compõem a noção de "condiçôes de vida", que é por ele entendida como um conjunto de processos que caracterizam e reproduzem a forma particular de participar de cada grupo de população no funcionamento do conjunto da sociedade, ou seja, na produção, distribuição, e consumo de bens e serviços e ainda nas relaçooes de poder que caracterizam a organização política. Seguindo esse caminho, ele fala que reproduzir o homem significa reproduzi-lo não só biologicamente, mas também nas suas relações ecológicas, políticas e econômicas - mediadas pelo processo de produção e de trabalho - e nas formas de consciência e conduta. Ainda para Castellanos, essa delimitação, no caso dos estudos sobre saúde e condições de vida, terá consequências na definição das unidades de análise e, supõe-se, nas variáveis (interações, comportamentos) específicas do nível sob estudo: contextuais (nível imediato superior) e analíticas (nível imediato inferior).

Para Samaja (2007), outro autor em que este estudo se baseia, os problemas de saúde se situam em uma encruzilhada de múltiplas disciplinas e enfoques metodológicos e exigem integrar todas as perspectivas na compreensão dos fatos concretos. Ele coloca duas séries de conceitos fundamentais sobre a saúde e um princípio metodológico:

Primera serie: la vida humana se describe de maneira esencial como una compleja articulación de processos histórico-sociales de producción y reproducción de sí misma, a lo largo de los quales surgem tensiones, conflictos que motivan acciones de reparacción o de transformacción (SAMAJA, 2007, p.47, grifo do autor).

Por meio dessa primeira série de conceitos, Samaja delineou um modelo que situa as questōes referentes às "situações de saúde" e "condições de vida" em um contexto amplo. Para ele, a compreensão da saúde é inerente à compreensão 
das condições de vida e das relações estabelecidas em um determinado espaço da reprodução social.

Segunda série: los resultados de aquellos procesos histórico-sociales se configuran a manera de estratos, en diversos niveles de integración, ordenados como jerarquías estructurales y funcionales; que se organizan en sentido ascendente, seguiendo el sentido de su producción y en sentido descendente, seguiendo el sentido de la reproducción, de modo que los estratos superiores regulan los procesos de los inferiores, pero bajo ciertas condiciones que limitan su validez mediante la exigência de eficácia (SAMAJA, 2007, p. 47, grifo do autor).

Por meio desses conceitos, discutiu os níveis de integração que conformam o fenômeno humano - em particular as articulações entre o individual e o coletivo - e propôs superar duas séries de erros simétricos, dois tipos extremos de reducionismo: o reducionismo fisicalista, que reduz a noção de saúde aos níveis inferiores (do sistema complexo ao nível orgânico, celular ou molecular); o reducionismo holista que remete todo fato de saúde aos níveis superiores (os modos de produção, a estrutura de classes ou as formações culturais);

Principio metodológico: las investigaciones cientificas en el tema salud deben dirigirse no solo sobre los aspectos estructurais y funcionales de su objeto, sino también, y ante todo, sobre la historia, entendida de dos maneras - de manera divergente (como la presencia del futuro, los procesos de surgimiento de nuevos niveles de realidades a partir de los conflictos y desequilibrios de los niveles precedentes); $y$ de manera convergente (como la presencia del pasado en lo actual, en los ciclos reproductivos de los niveles anteriores por medio de los cuales se mantiene lo ya existente). (SAMAJA, 2007, p. 47, grifo do autor).

Para o autor, esses conceitos vão mais além da noção de nexo causal e concebem a noção de nexo funcional e ação comunicacional. Esse nexo só pode se dar na condição em que as partes disponham de sensibilidade no contexto onde operam e no qual o todo possa se apoderar da ação que desenvolvem suas partes.

\section{A reprodução social e a situação de saúde}

O dilema se as situações de saúde integram as condições de vida ou não foi tratado por Samaja (2007), após profundas reflexóes sobre o papel da reprodução social na definição de saúde e seu cuidado. O dilema inevitável apontado por esse autor é um indicador da necessidade de superação reducionista. Samaja (2007), em seus estudos de epistemologia da saúde, aprofunda a ordem descritiva hierárquica da reprodução social e aporta uma sistematização que pode libertar do dilema referido. Para tal adota uma concep̧ção processual e epigenética da totalidade e propõe um dos problemas em concreto. Para ele, ambos se determinam mutuamente: 
"El tratamiento en concreto" implica que la realidad existe aquí y ahora como unidad de

una gran diversidad de componentes que se ha formado históricamente, pero que se actualiza en el presente de manera diversa [...]. "La concepción procesual y epigenética" nos invita a reconocer que las totalidades concretas se modifican y alteran sus cualidades a lo largo del tiempo, de manera que lo que es predominante en un momento pasa a ser secundario o subordinado en otro momento; que lo que es actual, en un cierto momento, pierde actualidad, y lo que era potencial llega a ser actual (SAMAJA, 2007, p. 131, grifo do autor).

A situação de saúde de indivíduos ou grupos é um fenômeno que se expressa no âmbito individual e coletivo, que pode ser compreendido como um processo da reprodução social em que se imbricam as reproduções biológica, ecológica e política, econômica e das formas de consciência e da conduta. O importante para Samaja (2007) éo reconhecimento dosâmbitos privilegiados da Reprodução Social em cada grupo humano específico. No caso, o objeto de estudo das disciplinas que se situam no campo da saúde abrange os problemas, as representações e as estratégias de ação apresentadas no curso da reprodução da vida social, possibilita a visão ampliada do seu campo, uma vez que não localiza os problemas apenas na área biológica, nem somente da reprodução psicológica, mas inclui os problemas nas demais dimensões da totalidade da reprodução social.

A lógica histórico-formal que precede toda a entidade processual existe como sistema complexo adaptativo. Cada ciclo reprodutivo introduz, necessariamente, modificaçōes em suas condições prévias, como cita o autor:

Cada ciclo de reproducción tiende a producir el mismo tipo de existencia (o de ciclo), pero nunca pode repetir la existencia o el ciclo singular que acaba de transcurrir [...] toda reproducción es una nueva producción, $y$, como cada singular es diferente a todo otro singular aunque "represente" o "encarne" a un mismo tipo, cada reproducción va poniendo - lenta, pero inexorablemente - las bases de la transformación de aquello que reproduce. (SAMAJA, 2007, p.107, grifo do autor).

Assim, é possível se fazer uma caracterização do conteúdo geral de cada um dos ciclos; fazendo-se abstração da hierarquia presente em sua estrutura, localizamse as seguintes reproduçôes constitutivas: biológica (bioindividual e biocomunal); da autoconsciência e da conduta (comunal-cultural); ecológico-política (estatal) e reprodução tecnoeconômica (societal). Considera-se que os ciclos são formações que têm uma ordem constitutiva hierárquica do tipo ascendente, em que a reprodução biocomunal pode realizar, de maneira autossuficiente, todas as demais funções reprodutivas.

Segundo a condição epigenética, a reprodução biológica (biocomunal) é a que permite aos membros da sociedade reproduzirem suas condições de 
organismos vivos sociais no dia a dia, sendo que o produto dessa reprodução é o organismo, estruturalmente, acoplado em redes de interações. Esse foi o processo que permitiu, na ontogenia, um fenômeno essencialmente novo e diferente de superação do organismo multicelular isolado.

A reprodução da autoconsciência e da conduta (comunal-cultural) é a capacidade que permite ao ser humano ser produtor de redes simbólicas, de elaboração e transmissão de experiências e aprendizagem (cultura), a partir de dois conceitos: a socialização primária (processo formativo, normalmente, desenvolvido pela família com relações de parentesco) e a socialização secundária (ou educação) que se encontra a cargo de estruturas societais ou estatais, como a Escola e, subsidiariamente, todas as demais instituições da sociedade civil e os meios de controle ideológico (SAMAJA, 2007, p. 111).

A reprodução ecológico-política (estatal) faz referência aos processos pelos quais os indivíduos ou grupos humanos devem restabelecer as relações de interdependência entre as condições territoriais/ambientais com as demais (comunais-culturais e biocomunais) (SAMAJA, 2007, p. 113). A esfera das relações sociais é responsável pelos processos de reprodução ecológica, como reprodução do macro ambiente social. Nela estão incutidas as relações materiais e jurídicas que constituem o sentido originário do Estado, o qual fixa sua essência na função de resguardar os vínculos das comunidades com seus ambientes territoriais de desenvolvimento e das associações civis com seus ambientes técnico-organizacionais que se formam na socialização secundária e se expressam através da ideia do "público" (SAMAJA, 2000, p. 82). Aqui o autor se inspira no conceito de território e desenvolvimento de Milton Santos (1996; 2004). ${ }^{1}$

A reprodução tecnoeconômica (societal) se refere aos processos pelos quais o ser humano deve produzir seus meios de vida, mediante atividades produtivas e os pactos de associação que os indivíduos estabelecem para efetuar a atividade de trabalho e os intercâmbios de bens. Para Samaja, as atividades econômicas não têm como objeto imediato a produção do organismo próprio, nem sequer a produção de bens para o organismo próprio, senão a produção de bens em todas as suas escalas de mediação que, posteriormente, incorporam-se à reprodução biológica e a da autoconsciência e da conduta. Essa dimensão está relacionada à reprodução dos meios de vida, mediante os processos especificamente destinados à produção, à distribuição, ao intercâmbio, através de diversos pactos de associação (SAMAJA, 2000, p. 60). 
Samaja considera, na caracterização da reprodução social, que a formação biocomunal é a que replica as demais funçôes reprodutivas na sua base e é por elas ressignificada.

\section{Utilização do conceito de reprodução social para construção de uma estrutura conceitual de determinação socioambiental da dengue}

O caráter complexo da dengue, devido às inter-relaçóes das três ecologias do homem, do vírus e do vetor -, sendo o ambiente o elemento comum que transita entre elas, já tem sido discutido por diversos autores (AUGUSTO; CARNEIRO; MARTINS, 2005; DONALÍSIO, 1999; PIGNATTI, 1996) e vem demonstrando necessidade de se repensar as abordagens adotadas no controle dessa enfermidade. Nesse sentido, o contexto da reprodução social é uma necessidade a ser incorporada na determinação socioambiental da dengue.

A discussão sobre fator de risco, condicionantes, vulnerabilidade, contexto e determinação social no processo de adoecimento são temas candentes na Saúde Pública e na epidemiologia (BUSS; PELLEGRINI FILHO, 2007; DAHLGREN; WHITEHEAD, 1991; CASTELLANOS, 1997). Atualmente, a determinação social ganha enfoque destacado em razão das políticas de redução de iniquidades em saúde. É nas intervenções que se verificam os maiores desafios para operacionalização desses conceitos, visando à transformação dos contextos nocivos para a vida e para a saúde.

A necessidade de intervir sobre a "rede de acontecimentos", como citou Castellanos (1997), que condiciona a ocorrência de doenças em um ambiente coletivo, deve-se dar a partir do conhecimento dos elementos das condições de vida existentes que participam do processo de determinação social da enfermidade. Esse autor, ao abordar a questão do ciclo reprodutivo, em que operam fatores que favorecem e/ou desfavorecem a situação de saúde dos indivíduos e das populações, o faz com propriedade. Por outro lado, a Saúde Pública nem sempre cumpre com essa missão, podendo, às vezes, a depender de seus modelos e práticas, ser promotora de iatrogenias individuais, coletivas e ambientais. Assim, se predominam fatores negativos - que aqui serão chamados de situação de risco - a situação de saúde se deteriora. 
O entendimento de risco aqui é referido não apenas como a medição da ocorrência de eventos, mas reconstruído dentro de uma nova abordagem paradigmática da Teoria da Complexidade, que considera a natureza simbólica, complexa e singular da relação entre saúde-doença-cuidado e os processos sociais, como apresentam Almeida Filho e Coutinho (2007). Esses autores consideram, ainda, no conceito de risco, a necessidade de atualizar-se e a capacidade de articular-se aos desenvolvimentos conceituais e metodológicos, contribuindo com estratégias capazes de abordar objetos complexos emergentes. Incorpora, também, o conceito de "risco contingencial" como operador do recém-construído campo de práticas da Promoção da Saúde e da Vigilância à Saúde.

Segundo esses autores, a tentativa de apresentar correlações entre variáveis com nexos causais entre fenômenos complexos, tornando a causa como processo natural, é simplória e fácil de refutar. Ao discutirem a "multicausalidade", acrescentam, ainda, que esse termo nada informa em relação à natureza complexa das conexões ou funções de risco. A expressão "multicausalidade" não indica qualquer aumento substancial do nível de complexidade - multiplicar causa não resolve as limitações fundamentais do causalismo. Tal abordagem se refere, exclusivamente, à complicação e não à complexidade. Assim, Samaja (2006) comenta que as relaçôes entre os elementos de um sistema constituem relação de "parte-extrapartes", relação de partes alienadas de uma totalidade, frente à distinção entre causa e doença. $O$ que desafia é a compreensão das conexōes existentes na determinação social das doenças e, neste caso em particular, os nexos presentes na determinação da dengue.

A dengue pode ser compreendida no processo de reprodução social, mediante indicadores das diversas dimensões que a compõem, tais como o biológico (morbidade, mortalidade), autoconsciência e da conduta (insatisfação com atenção da assistência, falta de cuidado com o ambiente) que surgem no âmbito dos grupos populacionais de uma sociedade. Dessa maneira, a reprodução social se mostra útil para explicar a interdependência das várias dimensões que compõem o processo de determinação social da dengue em cada nível de abordagem que se apresente.

De alguma forma, o problema dos modelos de controle vetorial da dengue e o modelo de controle de pragas agrícolas têm em comum a hegemonia da utilização de produtos químicos. Trata-se de um modelo que se sustenta nos modelos lineares "causa-efeito" e "dose-resposta", oriundos do positivismo (empirismo), 
que também deu sustentação aos modelos de mono e multicausalidade. Poder-se-

ia, ainda, acrescer nessa discussão o aspecto ideológico, que sustenta o discurso de que o produto químico é necessário para, no caso da agricultura, matar a fome da humanidade e no da saúde pública, salvar a humanidade das epidemias.

\section{A necessidade de uma gestão integrada e participativa para o controle da dengue: o enfoque ecossistêmico em saúde}

Nos últimos oito anos, observa-se que as abordagens de controle utilizadas pelos programas oficiais, no Brasil, tanto no controle da doença quanto no enfrentamento das epidemias, se apresentaram semelhantes aos modelos adotados no continente asiático em décadas passadas (OMS, 2004).

Dentre as abordagens de controle de vetor que têm sido muito difundidas em todo o mundo, tanto pela eficácia como pela diminuição de resistência dos vetores, encontra-se a abordagem de controle biológico do vetor da dengue. Os agentes utilizados nesse controle são organismos capazes de parasitar ou predar mosquitos em suas várias fases evolutivas. Pesquisas estão sendo feitas com base no uso de algumas espécies predadoras (peixes larvófagos, copépodos), parasitas (nematóides) e patógenos (protozoários-microsporídios, Bacillus produtores de toxinas, fungos e vírus). Estes últimos agem como inseticidas de natureza biológica.

A alternativa de larvicidas biológicos tem sido implementada (PARRAHENAO; GARCÍA-PAJÓN; COTES-TORRES, 2007; RÉGIS et al., 2000). Hoje, produtos comerciais à base de Bacillus thuringiensis subsp.israelensis (Bti), com boa atividade larvicida contra Aedes, podem ser empregados em larga escala.

A necessidade de estratégias integradoras e de caráter transdisciplinar tem sido também identificada. A Estratégia Geral Integrada (EGI) e a Abordagem Ecossistêmica se caracterizam por apresentar maior ênfase na vigilância dos fatores ambientais, tendo como principal elemento o "homem", sua ontogênese e o seu ambiente planetário, em que todos os seres vivos devem viver em completa integração. Nesse contexto, a abordagem ecossistêmica em saúde humana (Ecosaúde) surge para responder a uma lacuna na atualidade e frente a incertezas apresentadas no processo dinâmico de interação entre os seres vivos e a ação humana. Lebel (2005) considera a gestão dos ecossistemas o que se atinge com a busca do equilíbrio da saúde e bem-estar do ser humano (caráter antropocêntrico), não apenas a proteção do meio ambiente. Outra característica 
é a adoção de um processo de investigação que não esteja restrito aos científicos, de modo que os conhecimentos adquiridos possam integrar-se à vida das pessoas. Esse autor propõe o método de investigação que inclua, também, os membros da comunidade, representantes do governo e outros interessados. No que se refere aos atores com poder decisório, inclui aqueles com influência informal baseada em seu conhecimento, experiência e reputação (LEBEL, 2005, p. 9).

Em decorrência da necessidade de participação nesses três grupos, o enfoque de Ecosaúde segundo Lebel (2005, p. 10), se baseia em três pilares metodológicos:

La transdisciplinariedad implica una visión de amplio alcance de los problemas de salud relacionados con el ecosistema. Esto requiere total participación de los tres grupos mencionados y valida su completa inclusión.

La participación se pretende lograr consenso y cooperación, no solo dentro de la comunidad, de los científicos y de quienes toman las decisiones, sino también entre ellos.

La equidad compreende el análises de los respectivos papeles de hombres y mujeres y de los diferentes grupos sociales. En la evaluación del género se reconoce que los hombres y las mujeres tienen diferentes responsabilidades y diferentes grados de influencia en las decisiones.

A proposta daEcosaúde remeteà necessidade de estudar e promover intervençôes participativas na resolução de problemas complexos, compreendendo desde questôes de saúde humana a aspectos socioambientais. A transdisciplinaridade aqui é entendida na forma de produção e integração de novos marcos lógicos e quando os cientistas de várias disciplinas abrem espaço para a participação dos indivíduos da comunidade onde estudam e dos tomadores de decisão (LEBEL, 2005). Os marcos positivos de referência no campo de ação se dão com o engajamento em transformações que visem à sustentabilidade social.

O marco conceitual do enfoque ecossistêmico da Ecosaúde se emprega para analisar os vínculos entre os ecossistemas e a saúde humana, à luz da situação de controle da dengue e ao uso de inseticidas químicos no ambiente. Ao não considerar possíveis riscos para a saúde humana, ao mesmo tempo não se promove o empowerment da comunidade para a compreensão dos determinantes sociais e locais na causalidade da dengue. Assim, a abordagem ecossistêmica torna-se cada vez mais aceita como uma maneira de fazer uma descrição explícita da ligação entre os seres humanos e seus ambientes biofísico, social e econômico, a fim de identificar e implementar abordagens sustentáveis 
para melhorar a saúde humana (BRINCEÑO-LEÓN, 2009; FORGET;

LEBEL, 2001; WALTNER-TOEWS, 2001).

\section{Sistematização das situações de riscos percebidas no território em um modelo compreensivo/explicativo que atenda a complexidade da determinação multidimensional da dengue}

$\mathrm{Na}$ elaboração teórica das situações de risco relacionadas com a transmissão da dengue, a reprodução social foi utilizada como a categoria de análise para sistematizar as possíveis situaçōes observadas, em todas as suas dimensões: biocomunal, da consciência e da conduta, ecológica/política e técnico-econômica (SAMAJA, 2007).

$\mathrm{O}$ modelo proposto pretende uma visão integral que utilizou os resultados das diversas pesquisas avaliativas dos programas nacionais de controle de Dengue (AUGUSTO et al, 2000; SANTOS; AUGUSTO, 2005; NOVAES et al, 2006), em que foram levantados vários elementos que são sistematicamente desconsiderados nas intervenções para controle dessa endemia. A análise desses estudos subsidiou a sistematização das possíveis situações de risco, seguindo também a perspectiva de uma abordagem complexa.

O modelo compreensivo construído pode favorecer o planejamento integrado para o micro e o macrocontexto. O nível contextual de abordagem considerado poderá ser o domicílio, uma pequena comunidade, o bairro e a cidade, construindo uma hierarquia para as ações.

A proposição da abordagem ecossistêmica requer que, para a identificação das situações de risco, deve-se respeitar os pilares metodológicos da transdisciplinaridade, equidade e participação. Para a transdisciplinaridade, é requerida uma pergunta condutora comum a todas as disciplinas mobilizadas. No caso deste ensaio, a pergunta condutora foi: quais são as situaçôes de risco para transmissão da dengue, considerando-se as diversas dimensões da "reprodução social da saúde" no nivel local?

Com base nessas reflexões, foi desenhado um esquema para a modelagem proposta neste estudo, que possibilitou visualizar as inter-relações das dimensões envolvidas na produção e reprodução da doença, nos níveis de micro e macrocontexto no território da ação (figura 1). 


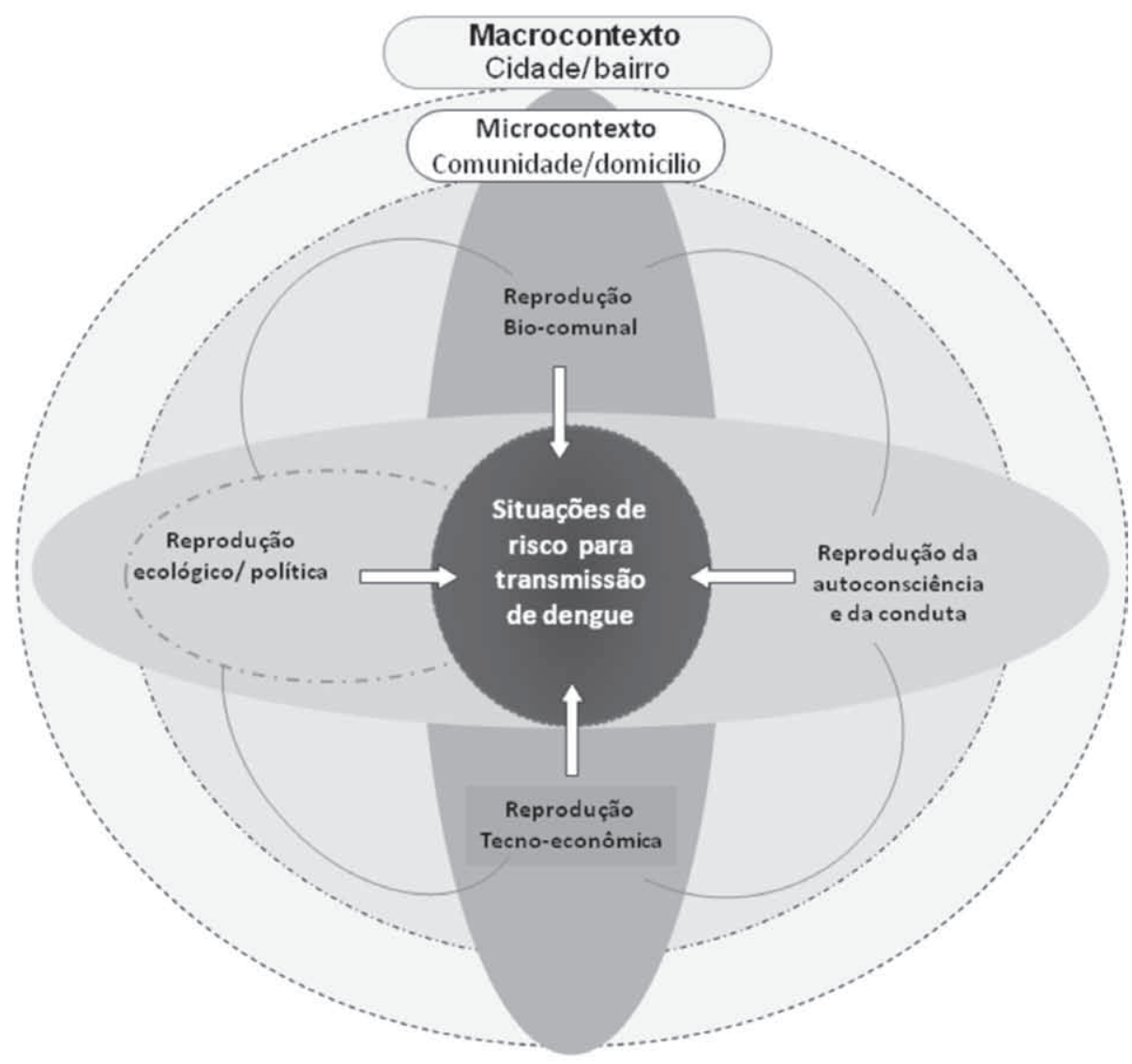

Estrutura conceitual

Fonte: Adaptado de Augusto (2007).

Entende-se que na reprodução biológica se podem encontrar elementos referentes ao vírus, ao vetor e ao ser humano exposto e infectado. Trata-se de três ecologias em interação, mediadas pelo contexto socioambiental. Quanto ao vírus, elencam-se os seguintes elementos envolvidos: a diversidade de sorotipos em circulação (DENV1, DENV2, DENV3, DENV4); o conhecimento incompleto da dinâmica da circulação viral, gerando confusão e incertezas; a virulência das cepas; a quantidade vírus inoculados no hospedeiro; a circulação prévia de outros vírus; o intervalo de tempo ocorrido entre as infecções; a ordem sequencial das infecções dos quatro sorotipos. Quanto ao vetor, sabe-se que há enorme 
robustez biológica, com grande capacidade de adaptação, incluindo a resistência

a inseticidas, o caráter antropofílico, a densidade, a dispersão, a competência vetorial. Quanto ao ser humano exposto ou infectado, vários aspectos devem ser considerados: vulnerabilidade socioambiental; susceptibilidade individual (idade, raça, doenças pré-existentes, estado nutricional, intervalo entre infecçôes); baixa resposta imunológica; imunidade de grupo; mecanismos fisiopatológicos das formas graves não totalmente conhecidas e outras ocorrências. Entre estes aspectos é importante ressaltar o acometimento em maior número das crianças.

$\mathrm{Na}$ reprodução da autoconsciência e da conduta, considera-se a baixa consciência ecológica, alto consumo de produtos descartáveis, inadequado armazenamento de água, destinação inadequada de resíduos, desconhecimento sobre a doença e sua forma de transmissão e controle, autodiagnóstico e automedicação, uso de inseticidas, baixa autonomia, cuidado inadequado com os recipientes de água, pouca participação em organizaçôes comunitárias.

$\mathrm{Na}$ esfera da reprodução ecológico/política ou estatal, a análise do Programa de Controle da Dengue revela ser um modelo vertical, não participativo e químicodependente. Com falta de ações integradas e articuladas intersetorialmente; ausência de procedimentos avaliativos contextualizados; inadequação de infraestrutura urbana (habitação e saneamento ambiental); baixos investimentos em educação; insuficiente acesso aos serviços de saúde; fácil adaptação do vetor ao modelo de produção e consumo da sociedade urbana contemporânea e ao seu estilo de vida, facilita a dispersão, sobrevivência e alto grau de adaptação, com perspectiva de agravamento em face das mudanças climáticas e alterações da biodiversidade.

$\mathrm{Na}$ reprodução tecno-econômica ou societal, as seguintes situações de risco favorecedoras para a transmissão da dengue são consideradas: baixa renda, alto custo do programa de controle vetorial e de hospitalização, alto nível de absenteísmo no trabalho.

Como pode ser visto, as situações de risco envolvidas na transmissão da dengue não são apenas aquelas relacionadas ao vetor; vê-se que, na dimensão biológica, devem ser considerados também os aspectos do vírus e do ser humano, individual e coletivamente. Mesmo em relação ao vetor, percebem-se outras dimensões não consideradas pelo programa oficial, pois sua capacidade adaptativa está condicionada ao modo de vida da população que, por sua vez, apresenta um padrão de consumo que se relaciona com o modo de produção e estilo de vida. 
$\mathrm{O}$ entrelaçamento desses elementos e de suas dimensóes evidencia a complexidade existente no problema da transmissão da dengue e que deve orientar as políticas públicas, não restrita ao setor saúde, e que devem atuar sobre todo o processo de determinação social da dengue. A manutenção do modelo químico dependente e, de certa forma, paternalista, não favorece uma abordagem ecossistêmica, mantendo-o fragmentado, vertical e pouco participativo.

O modelo construído no âmbito comunitário com a participação social e os técnicos locais pode ser útil no redirecionamento das açôes de acordo com as peculiaridades do contexto local.

\section{Considerações finais}

A compreensão da complexidade das interações que se dão entre os vários elementos envolvidos com a transmissão da dengue leva à procura por abordagens integradas, não parciais, que abranjam a globalidade desses elementos e suas conexões. Assim, pensou-se a utilização da abordagem ecossistêmica para esse problema. Essa abordagem considera essencial entender as formas de participação e equidade existentes nos contextos locais, exige um olhar de várias disciplinas em como se dá essa relação na compreensão da determinação do processo saúde-doença.

Discutir situaçôes de risco também remonta à questão das vulnerabilidades e iniquidades em saúde, sendo aqui consideradas as manifestações mensuráveis de injustiça social, representadas pelos diferenciais na possibilidade de adoecer e morrer. Essas vulnerabilidades também se originam de condições heterogêneas - não acesso a bens e serviços, inclusive os de saúde. A intervenção sobre as situaçôes de risco pode significar um ganho para a vigilância epidemiológica e a saúde e deve ir além das medidas lineares de interrupção da cadeia de transmissão de uma doença.

A modelagem construída buscou a compreensão sistêmica dos elementos envolvidos com o processo de transmissão da dengue no âmbito comunitário, de forma a contemplar os diversos contextos existentes. A capacidade de identificar cada um desses elementos e sua dimensão foi um desafio que se verificou durante a construção proposta. Como é bem citado por Garcia (2002, p. 55), um sistema não pode ser descrito adequadamente, nem seu funcionamento explicado, pela mera adição de enfoques parciais provenientes de estudos independentes de cada um dos seus componentes. Fica clara a necessidade de entendimento de um 
problema como a dengue, a partir da identificação de cada um dos componentes envolvidos e dos seus nexos.

A supremacia da dimensão biológica, no que se refere à sobrevivência das espécies e à clínica da doença é claramente evidenciada no caso da dengue. A força da reemergência das infecções causadas pelos quatro tipos de vírus tem sido um fenômeno relevante, quando se discute a magnitude da doença (GUBLER; CLARCK, 1995; GUBLER; MELTZER, 1996; KOURI, 2006).

A falta da percepção de risco sobre as substâncias químicas demonstra o paradoxo a que assistimos na atualidade, como refere Castellanos (1997): apesar do explosivo desenvolvimento técnico e tecnológico e da extensa produção de pesquisas epidemiológicas, no mundo contemporâneo, cada vez mais, a epidemiologia contribui menos para a compreensão dos problemas de saúde das populações e cada vez mais as intervenções de saúde pública tendem a se concentrar em intervenções sobre indivíduos. Assim, a modelagem construída para a compreensão das situações que estão envolvidas na transmissão da dengue no nível local, o uso da categoria de análise da reprodução social permitiram compreender como os elementos estão implicados com o problema e se relacionam de forma interdependente, na produção das situações de risco para a transmissão da dengue. É um modelo compreensivo, podendo ser útil pedagogicamente para as intervenções e nas avaliações de efetividade dos programas, por contemplar o problema na sua multidimensão, voltado à superação do modelo tradicional de tipo linear, de controle vetorial.

\section{Referências}

ALMEIDA FILHO, N.; COUTINHO, D. Causalidade, contingência, complexidade: o futuro do conceito de risco. Physis: revista de saúde coletiva, Rio de Janeiro, v. 17, n. 1, p. 95-137, 2007.

AUGUSTO, L.G.S. et al. Avaliação crítica do programa de erradicação do Aedes aegypti: consideraçôes técnicas para medidas de controle. Revista do IMIP, Recife, v. 14, n. 1, p. 90-97, 2000. AUGUSTO, L.G.S. Projeto apresentado ao edital do International Developement Research Center. Recife, 2007. Mimeografado.

AUGUSTO, L.G.S.; CARNEIRO, R.M.; MARTINS, P.H. Abordagem ecossistêmica em Saúde: ensaios para o controle de dengue. Recife: Ed. Universitária da UFPE, 2005.

BRAGA, I.A.; VALLE, D. Aedes aegypti: histórico do controle no Brasil. Epidemiologia e serviços de saúde, Brasília, v. 16, n. 2, p. 113-118, 2007. 
BRASIL. Ministério da Saúde. Casos notificados de dengue, Brasil, grandes regiōes e unidades federadas, 1997 a 2007. Brasília, 2008. Disponível em: <http://portal.saude. gov.br/portal/ arquivos/pdf/tabela_dengue2007.pdf>. Acesso em: 16 abr. 2008.

BRICEÑO-LEON, R. La enfermedad de Chagas en las Américas: una perspectiva de ecosalud. Cadernos de saúde pública, Rio de Janeiro, v. 25, supl. 1, p. 71-82, 2009.

BUSS, P.; PELLEGRINI FILHO, A. A saúde e seus determinantes. Physis: revista de saúde coletiva, Rio de Janeiro, v. 17, n. 1, p. 77-93, 2007.

CASTELLANOS, P.L. Epidemiologia, saúde pública, situação de saúde e condições de vida. Considerações conceituais. In: BARATA, R.B. (Org.). Condiçôes de vida e situações de saúde. Rio de Janeiro: Abrasco, 1997. p. 31-75.

DAHLGREN, G.; WHITEHEAD, M. Policies and Strategies to promote social equity in health. Stockholm: Institute for Future Studies, 1991.

DONALISIO, M. R. O Dengue no espaço habitado. São Paulo: Hucitec, 1999.

FORGET, G.; LEBEL, J. An ecosystem approach to human health. International journal of occupational medicine and environmental health, Lodz, v. 7, n. 2, S1-S38, 2001.

GARCIA, R. O conhecimento em construção: das formulações de Jean Piaget à teoria dos sistemas complexos. Porto Alegre: Artmed, 2002.

GUBLER, D.J.; CLARK G.C. Dengue/Dengue Haemorragic Fever: The emergence of a global health problem. Emerging infectious diseases, Atlanta, v. 1, n. 2, p. 55-58, 1995.

GUBLER, D.J.; MELTZER, M. Impact of dengue/dengue haemorragic fever on the developing world. Advances in virus research, New York, v. 53, p. 35-70, 1996.

KOURI, G. El dengue, un problema creciente de salud en las Américas. Revista Panamericana de Salud Pública, Washington, v. 19, n.3, p. 143-145, 2006.

LEBEL, J. Salud: un enfoque ecosistemico. Bogotá: Alfaomega, 2005.

LIMA, V.L.C. et al. Dengue: inquérito sorológico pós-epidêmico em zona urbana do Estado de São Paulo (Brasil). Revista de saúde pública, São Paulo, v. 33, n. 6, p. 566-574, 1999. NOVAES, T.C.P. et al. Práticas Sanitárias em Controle de Dengue: questionamentos que continuam. Revista da Sociedade Brasileira de Medicina Tropical, Brasília, v. 39, n. 1, supl., p. 88, 2006.

ORGANIZAÇÃO MUNDIAL DA SAÚDE. Dengue and dengue haemorrhagic fever. Geneva, 2006. Disponível em: <http://www.who.int/mediacentre/factsheets/fs117/en>. Acesso em: 3 nov. 2006.

DengueNet. WHO's Internet-based System for the global surveillance of dengue fever and dengue haemorrhagic fever (dengue/DHF). Dengue/DHF, global public health burden. Weekly epidemiological Record, Geneva, v. 77, p. 300-304, 2002. Disponível em: <http://www.who.int/denguenet>. Acesso em: 10 jan. 2006. 
ponível em: <http://www.who.org>. Acesso em: 10 jan. 2004.

ORGANIZAÇÃO PAN AMERICANA DA SAÚDE. Dengue, 44th Directing Council, 55th session of the Regional Committee. Washington, 2003.

PARRA-HENAO, G.J.; GARCÍA-PAJÓN, C.M.; COTES-TORRES, J.M. Actividad insecticida de extractos vegelates sobre Aedes aegypti (Díptera: culicidae) vector del dengue em Colômbia. Revista CES Medicina, Bogotá, v. 21, n. 1, p. 47-54, 2007.

PIGNATTI, M.G. Saúde e ambiente: as práticas sanitárias para o controle do dengue no estado de São Paulo - 1985-1995. 1996. Dissertação (Mestrado) - Departamento de Medicina Preventiva e Social, UNICAMP, Campinas, 1996.

REGIS, L. et al. Efficacy of Bacillus sphaericus in control of the filariasis vector Culex quinquefasciatus in urban area of Olinda, Brasil. Transactions of the Royal Society of Tropical Medicine and Hygiene, London, v. 94, p. 488-492, 2000.

SAMAJA, J. A reprodução social e a saúde: elementos metodológicos sobre a questão das relaçôes entre saúde e condiçōes de vida. Salvador: Casa da Qualidade, 2000.

. Epistemología de la salud: reproducción social, subjetividad y transdisciplina. 1.ed. Buenos Aires: Lugar, 2007.

Epistemología y metodología: elementos para una teoria de la investigación científica. 3.ed. Buenos Aires: Ed. Universitaria de Buenos Aires, 2006.

SANTOS, M. A natureza do espaço: técnica e tempo, razão e emoção. São Paulo: Hucitec, 1996. Por uma outra globalização: do pensamento único à consciência universal. 11.ed. Rio de Janeiro: Record, 2004.

SANTOS, S.L. Avaliação das ações de controle da dengue: aspectos críticos e percepção da população - estudo de caso em um município do Nordeste. 2003. Dissertação (Mestrado em Saúde Pública) - Centro de Pesquisas Aggeu Magalhães, Fundação Oswaldo Cruz, Recife, 2003.

SANTOS, S.L.; AUGUSTO, L.G.S. Dengue: uma avaliação das ações do programa de controle. Cadernos Saúde Coletiva. Rio de Janeiro, RJ, v.13, n.1, p. 263 -280, 2005.

WALTNER-TOEWS, D. Uma abordagem ecossistêmica à saúde e suas aplicações às doenças tropicais e emergentes. Cadernos de saúde pública, Rio de Janeiro, v. 17, supl. p. 7-36, 2001.

\section{Nota}

${ }^{1}$ Samaja, durante os anos 1990 e nos primeiros anos do século XXI (até a sua morte, em fevereiro de 2007), colaborou com diversos programas de pós-graduação no Brasil, onde teve a oportunidade de conhecer com profundidade a literatura de Milton Santos, passando a admirá-lo e a incorporar suas formulações, incluindo um curso sobre "Métodos para uma epidemiologia Miltoniana", apresentado no CPqAM em 2003 (segundo informação da Profa. Lia Giraldo da Silva Augusto, 2009). 


\section{Abstract}

\section{Multidimensional model for dengue control: a proposal based on social reproduction and risk situations}

This paper aims to present and discuss a comprehensive / explanatory model, of ecosystem approach, on the process of transmission of dengue in the levels of micro and macro context, from the identification of the risks involved. Dengue was considered a viral infectious disease of vectorial transmission that carries on its transmission dynamics, elements of the biological, behavioral, ecological, political and economic dimensions, that make it a complex problem and require a systemic approach to its control. Thus, for the construction of modeling, we used the theoretical framework of social reproduction of Juan Samaja and its conditions of macro and microcontext, and the operating ecosystem approach, which sought to answer the question driving this construction: what are the risk situations for the transmission of dengue, considering the different dimensions of "social reproduction of health" at the local level? The enlarged view of the interrelationships among the various risk situations involved in determining multidimensional dengue could guide the integrated management of actions of a disease control program, coordinated by the several sectors involved.

> Key words: dengue; prevention and control; risk; complexity; ecosystem approach. 